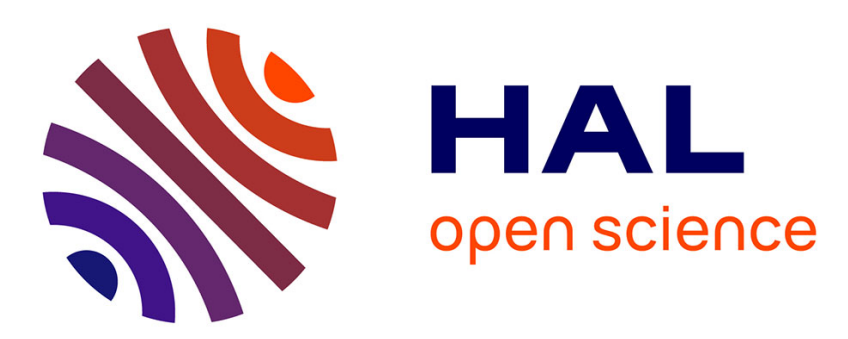

\title{
Selective and Efficient Iridium Catalyst for the Reductive Amination of Levulinic Acid into Pyrrolidones
}

Shengdong Wang, Haiyun Huang, Christian Bruneau, Cedric Fischmeister

\section{To cite this version:}

Shengdong Wang, Haiyun Huang, Christian Bruneau, Cedric Fischmeister. Selective and Efficient Iridium Catalyst for the Reductive Amination of Levulinic Acid into Pyrrolidones. ChemSusChem, 2017, 10 (21), pp.4150-4154. 10.1002/cssc.201701299 . hal-01653156

\section{HAL Id: hal-01653156 \\ https://hal-univ-rennes1.archives-ouvertes.fr/hal-01653156}

Submitted on 1 Dec 2017

HAL is a multi-disciplinary open access archive for the deposit and dissemination of scientific research documents, whether they are published or not. The documents may come from teaching and research institutions in France or abroad, or from public or private research centers.
L'archive ouverte pluridisciplinaire HAL, est destinée au dépôt et à la diffusion de documents scientifiques de niveau recherche, publiés ou non, émanant des établissements d'enseignement et de recherche français ou étrangers, des laboratoires publics ou privés. 


\title{
Selective and Efficient Iridium Catalyst for the Reductive Amination of Levulinic Acid into Pyrrolidones
}

\author{
Shengdong Wang, ${ }^{[a]}$ Haiyun Huang, ${ }^{[a]}$ Dr. Christian Bruneau, ${ }^{[a]}$ and Dr. Cédric Fischmeister ${ }^{*[a]}$
}

\begin{abstract}
The catalytic reductive amination of levulinic acid (LA) into pyrrolidones with an iridium catalyst using $\mathrm{H}_{2}$ as hydrogen source is reported. The chemoselective iridium catalyst displayed high efficiency for the synthesis of a variety of $\mathrm{N}$-substituted 5-methyl-2pyrrolidones and $\mathrm{N}$-arylisoindolinones. $\mathrm{N}$-Substituted 5-methyl-2pyrrolidone was evaluated as a bio-sourced substitute solvent to NMP (N-Methyl-pyrrolidone) in the catalytic arylation of 2phenylpyridine.
\end{abstract}

Highly selective and efficient catalytic transformation of non-food biomass-derived platform compounds has been recognized as a key technology for problems faced with fossil resources. ${ }^{[1]}$ Levulinic acid (LA) which can be easily generated by acidic hydrolysis of carbohydrates is one of the most promising biomass feedstock for the synthesis of useful intermediates and fine chemicals. ${ }^{[2]}$ In this context, $\mathrm{N}$-substituted-5-methyl-2pyrrolidones are important core structural unit in organic chemistry which find applications in domains such as surfactants solvents and intermediates for ink or fibers. ${ }^{[3]}$ Despite several known methods including intramolecular hydroamination, ${ }^{[4]}$ hydroamination-cyclization ${ }^{[5]}$ and $\mathrm{N}$-alkylation, ${ }^{[6]}$ there is an ongoing interest for the development of general protocols for the synthesis of these pyrrolidone derivatives from renewable resources.

An early example of reductive amination of LA for the synthesis of pyrrolidones was reported by Frank in 1947. ${ }^{[7]} 1,5-$ Dimethyl-2-pyrrolidone was synthesized from levulinic acid and methyl amine in $74-77 \%$ yield employing Raney Nickel under harsh conditions $\left(140{ }^{\circ} \mathrm{C}, 70-140\right.$ bar $\left.\mathrm{H}_{2}\right)$. Several other heterogeneous catalysts have been described. Manzer ${ }^{[8]}$ reported a series of supported transition metals also operating under harsh conditions $\left(150-220{ }^{\circ} \mathrm{C}, 35\right.$ bar $\left.\mathrm{H}_{2}\right)$ for the transformation of levulinic acid and its esters into $\mathrm{N}$-alkyl-5methyl pyrrolidones. Cao, ${ }^{[9]} \mathrm{Xiao}^{[10]}$ reported several effective heterogeneous catalytic systems (hydrogenation \& transfer hydrogenation) but the substrate scope was limited. In 2014, Shimizu described a Pt-supported catalyst operating without solvent under mild conditions $\left(100{ }^{\circ} \mathrm{C}, 3\right.$ bar). These catalysts were very efficient with a broad variety of amines including sterically demanding amines. ${ }^{[11]}$ Recently, a number of heterogeneous catalyst were reported some of them operating under mild conditions. Catalyst recycling in batch mode or continuous flow operation are in general accessible with heterogeneous catalysts but selectivity issues are often observed. ${ }^{[12]}$ The first homogeneous catalytic system was

[a] S. Wang, H. Huang, Dr. C. Fischmeister, Dr. C. Bruneau Institut des Sciences Chimiques de Rennes Organometallics: Materials and Catalysis UMR 6226 CNRS, Université de Rennes 1,Campus de Beaulieu, F35042 Rennes Cedex, France

E-mail: cedric.fischmeister@univ-rennes1.fr

Supporting information for this article is available on the: reported by $\mathrm{Fu}$ in 2011. ${ }^{[13]}$ A ruthenium catalyst generated in situ from $\left[\mathrm{RuCl}_{2}(p \text {-cymene })\right]_{2}$ and a bulky phosphine ligand was used with formic acid as hydrogen source. This catalyst was efficient at $80{ }^{\circ} \mathrm{C}$ but required a high catalyst loading $(1 \mathrm{~mol} \%)$ and did not tolerate bulky amines. Efficient $\mathrm{Cp}^{*} \mathrm{Ir}$ catalysts were later reported by Xiao ${ }^{[14]}$ and Zhang. ${ }^{[15]}$ These catalyst operated in water under mild conditions $\left(80^{\circ} \mathrm{C}\right)$ by transfer hydrogenation using a formic acid/sodium formate mixture and hydrogenation, respectively. A variety of amines was tolerated but bulky amines were not evaluated. Indium, aluminum and boron-catalyzed reductive amination of levulinic acid using silanes as reducing agents were reported. ${ }^{[6,16]}$ Very good results were obtained but these catalysts suffered from some drawbacks such as high catalyst loading, excess of silanes (waste issue), high temperature and necessity to use organic solvents. Finally, some catalyst-free procedures have been reported. Even though good results were obtained, these procedures required high temperatures ${ }^{[17]}$ or the use of DMSO and triethylamine ${ }^{[18]}$ which make them less environmentally friendly.

All these results contributed to the development of efficient reductive amination of LA and made clear that bulky substituted amines are challenging substrates. Chemoselectivity is another problem in reductive amination of LA to lactams that should be considered carefully if reducible functional groups are also present in the targeted products. These two challenging issues have rarely been considered and only few studies dedicated to the chemoselective reductive amination of ethyl levulinate have been reported. ${ }^{[12 c, 16 a, 19]}$ Herein, we report a selective and efficient iridium-catalyzed hydrogenative amination of LA by primary amines to $\mathrm{N}$-substituted-5-methyl-2-pyrrolidones Various aliphatic amines and aniline derivatives including sterically demanding amines are reported. The chemoselectivity of the reaction was also evaluated using specific reagents containing reducible functional groups.

Recently, we reported that the zwitterionic iridium complex Ir1 featuring the 2,2'-dipyridylamine ligand is a highly efficient catalyst for the synthesis of $y$-valerolactone (GVL) by hydrogenation of LA in water $($ TON $=174000)($ Scheme 1$) .{ }^{[20]}$
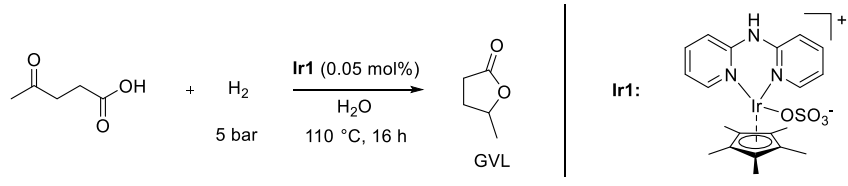

Scheme 1. Hydrogenation of LA with Ir1.

We assumed that this catalyst would also be a valuable candidate for the reductive amination of $\mathrm{LA}$. The reductive amination of LA with 4-methoxyaniline using $\mathrm{H}_{2}$ as hydrogen source was used as a model reaction for optimization of experimental conditions. The best conditions reported for LA transformation into $\mathrm{GVL}$ i.e. $110{ }^{\circ} \mathrm{C}$ for $16 \mathrm{~h}$ in water were first evaluated. As depicted in Table 1 (Entry 1), the desired pyrrolidone was obtained in $72 \%$ yield with concomitant 
formation of GVL. This result could be slightly improved by increasing the hydrogen pressure to 20 bar (Table 1, Entry 1). Other solvents were evaluated in order to prevent formation of GVL attributed to unfavorable conditions for the synthesis of the intermediate imine. This screening revealed that neat conditions were the most suitable for a selective transformation (Table 1, entry 2-5). A temperature of $110{ }^{\circ} \mathrm{C}$ was also necessary to ensure full conversion in a short time.<smiles>COc1ccc(N2C(=O)CCC2C)cc1</smiles>

Scheme 2. Reductive amination of levulinic acid.

Table 1.Optimization of reaction conditions ${ }^{[\mathrm{a}]}$

\begin{tabular}{cccccc}
\hline Entry & $\mathrm{T}\left({ }^{\circ} \mathrm{C}\right)$ & Solvent & $\begin{array}{c}\text { Conv. } \\
(\%)^{[\mathrm{b}]}\end{array}$ & $\begin{array}{c}\mathbf{A} \\
\text { Yield }(\%)^{[\mathrm{b}]}\end{array}$ & $\begin{array}{c}\text { B } \\
\text { Yield }(\%)^{[\mathrm{b}]}\end{array}$ \\
\hline 1 & 110 & $\mathrm{H} 2 \mathrm{O}$ & $95(100)^{[\mathrm{c}]}$ & $72(79)^{[\mathrm{c}]}$ & $23(21)^{[\mathrm{c}]}$ \\
2 & 110 & $\mathrm{MeOH}$ & 38 & 25 & 13 \\
3 & 110 & Toluene & 89 & 57 & 32 \\
4 & 110 & - & 98 & 98 & 0 \\
5 & 90 & - & 53 & 53 & 0 \\
\hline
\end{tabular}

[a] LA (2 mmol), 4-methoxyaniline (2 mmol), Ir1 (0.05 mol \%), $\mathrm{H}_{2} 5$ bar, 16 h. [b] ${ }^{1} \mathrm{H}$ NMR yield. [c] $\left(20\right.$ bar $\left.\mathrm{H}_{2}\right)$

With these optimized conditions in hands, the general applicability of this system was first demonstrated through the reductive amination of LA with a series of aniline derivatives. The reaction was not sensitive to electronic effects since both electron-donating and electron-withdrawing substituents did not hamper the formation of the corresponding pyrrolidones in high yields (Figure 1). Of note, the catalyst tolerated very bulky amines although catalyst loading needed to be increased to ensure high yields (Figure 2, 1e-1h). It is worth mentioning that 1f and $\mathbf{1 g}$ have been rarely reported (in moderate to good yields) whereas compound $\mathbf{1 h}$ has not been reported so far. The chemoselectivity of the catalyst was studied through the synthesis of compounds $\mathbf{1 i - 1 k}$. The amido and cyano groups were not reduced under our standard experimental conditions, however, at $110{ }^{\circ} \mathrm{C}$ the acetyl group in $\mathbf{1 j}$ was partially reduced leading to $10 \%$ of the corresponding hydroxyl compound. We have recently reported that acetophenone could be efficiently reduced with the same catalyst but under different experimental conditions $\left(130^{\circ} \mathrm{C}, \mathrm{H}_{2} \mathrm{O}\right.$ as solvent). ${ }^{[20]}$ This result demonstrates that chemoselectivity improvements may be achieved by optimizing the reaction conditions for each individual compound.

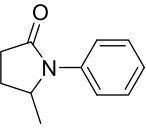

1 a, $90 \%$

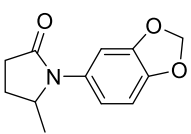

1d, $81 \%$

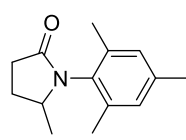

$1 \mathrm{~g}, 65 \%$

$92 \%(0.1 \mathrm{~mol} \%$ Ir 1$)$

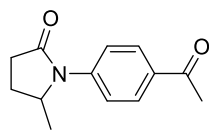

$1 \mathrm{j}, 85 \%[\mathrm{~b}]$

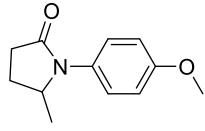

1b, $91 \%$

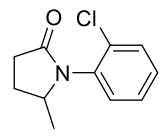

1 e, $75 \%$
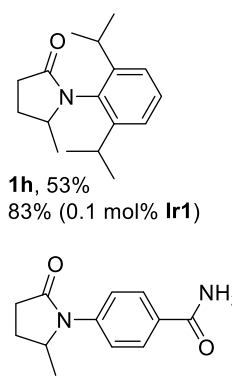

1 k, $92 \%$

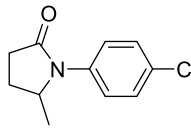

1c, $88 \%$

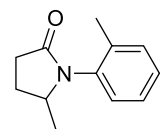

1f, $74 \%$

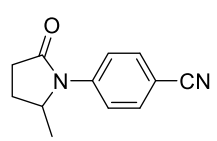

$1 \mathbf{1 i}, 93 \%$
Figure 1. Reductive amination of LA with aromatic amines: LA (2 mmol), Ir1 $(0.05 \mathrm{~mol} \%)$, amines $(2 \mathrm{mmol}), \mathrm{H}_{2} 5 \mathrm{bar}, \mathrm{T}=110^{\circ} \mathrm{C}, 16 \mathrm{~h}$, isolated yields. ${ }^{[\mathrm{b}]}$ $10 \%$ of alcohol obtained.

The reductive amination of LA with various linear and branched primary amines was also considered and led to the formation of the desired products in high yields (Figure 2, 2a-2f). Benzylamine derivatives also led to the corresponding pyrrolidones in very good yields (Figure $1, \mathbf{2 g}-\mathbf{i}$ ).<smiles>CC1CCC(=O)N1CCO</smiles>

2a, $90 \%$<smiles>CC(C)N1C(=O)CCC1C</smiles>

2d, $91 \%$

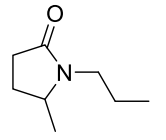

2b, $93 \%$

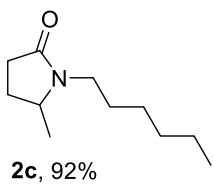

2c, $92 \%$

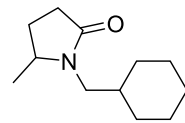

2f, $96 \%$

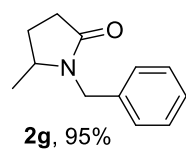

2e, $90 \%$

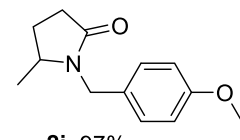

$\mathbf{2 i}, 97 \%$

Figure 2. Reductive amination of LA with aliphatic amines. conditions: LA (2 $\mathrm{mmol})$, Ir1 (0.05 mol\%), amines $(2 \mathrm{mmol}), \mathrm{H}_{2} 5 \mathrm{bar}, \mathrm{T}=110^{\circ} \mathrm{C}, 16 \mathrm{~h}$, isolated yield. 
To emphasize the potential of Ir1 in the context of biomass valorization, the synthesis of 1a was carried out in a sequential process starting from glucose (Scheme 3). Acid catalyzed hydrolysis of glucose leading to a mixture of levulinic acid, formic acid was first performed. Insoluble humins were removed by filtration and the $\mathrm{pH}$ of the resulting solution was adjusted to 7 by addition of sodium bicarbonate before addition of Ir1 and aniline. The reactor was pressurized with 20 bar of $\mathrm{H}_{2}$ and heated at $120{ }^{\circ} \mathrm{C}$ for $16 \mathrm{~h}$. This protocol led to the desired product in $31 \%$ isolated yield. This moderate result is in the same range of reported procedures ${ }^{[13]}$ and results essentially from the formation of humins in the first step of the process.

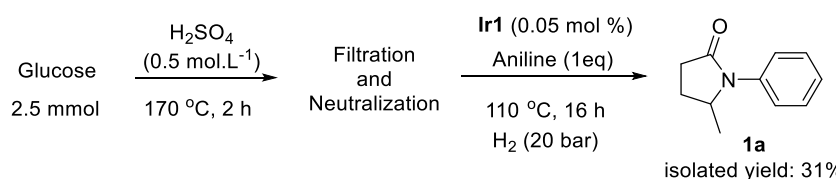

Scheme 3. Sequential procedure for the synthesis of $\mathbf{1 a}$.

To further extend the generality of this catalytic system, the reaction of 2-formylbenzoic acid with amines to generate $\mathrm{N}$-arylisoindolinone was evaluated (Scheme 4).

$$
\text { R-NH }
$$

Scheme 4. Synthesis of $N$-subsituted isoindolinones.

$\mathrm{N}$-Substituted isoindolinones are common compounds with important biological activities which represent an attractive target for organic synthesis and a valuable skeleton for drugs such as indoprofen. ${ }^{[21]} 2$-Formylbenzoic acid could be converted to $\mathrm{N}$ subsituted isoindolinones in good to excellent yields (80-98 \%) upon reaction with aromatic or aliphatic amines (Figure 3 ). This reaction shared the same feature than the reductive amination of LA as both electron donating and electron withdrawing substituents were tolerated. In the same manner, sterically hindered amines led to the corresponding compounds in high yields.

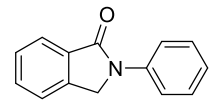

3a, $98 \%$<smiles>COc1ccc(N2Cc3ccccc3C2=O)cc1</smiles>

$3 d, 93 \%$<smiles>CC(C)c1cccc(C(C)C)c1N1Cc2ccccc2C1=O</smiles>

$3 g, 80 \%$

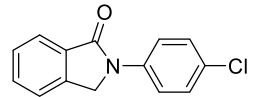

3b, $94 \%$

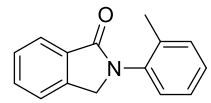

3e, $91 \%$

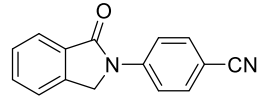

3c, $94 \%$
Figure 3. Reductive amination of 2-formylbenzoic acid : 2-Formylbenzoic acid (2 mmol), Ir1 (0.05 mol \%), amines ( $2 \mathrm{mmol}), \mathrm{H}_{2}, 5$ bar, $110{ }^{\circ} \mathrm{C}, 16 \mathrm{~h}$, isolated yields.

$\mathrm{N}$-Substituted-5-methyl-2-pyrrolidones are structurally related to $\mathrm{N}$-methylpyrrolidone (NMP), which is widely used as polar aprotic solvent in the chemical industry. However, this fossilsourced solvent presents important safety issues due to its toxicity. Not surprisingly, it is subject to severe regulations in particular in the pharma industry where its substitution is recommended. ${ }^{[22]} \mathrm{N}$-Substituted-5-methyl-2-pyrrolidones can be regarded as bio-sourced analogues of NMP. The potential use of these compounds as NMP substitute was investigated using a ruthenium-catalyzed arylation of 2-phenylpyridine which is generally performed in NMP (Scheme 5). ${ }^{[23]} \mathrm{N}$-Propyl-5-methyl2-pyrrolidones $\mathbf{2 b}$ was selected as a compound with reasonable boiling point $\left(248{ }^{\circ} \mathrm{C}\right)$ as compared to NMP $\left(202{ }^{\circ} \mathrm{C}\right) .{ }^{[24]}$ As depicted in Scheme 5, both solvents led to similar conversions but slightly different selectivities. The influence of the solvent on the selectivity would require deeper investigations but these results clearly prove that bio-sourced $\mathrm{N}$-substituted-5-methyl-2pyrrolidones could be used as NMP substitute. Of course, toxicity and hazard data of this potential candidate will be needed for full consideration.

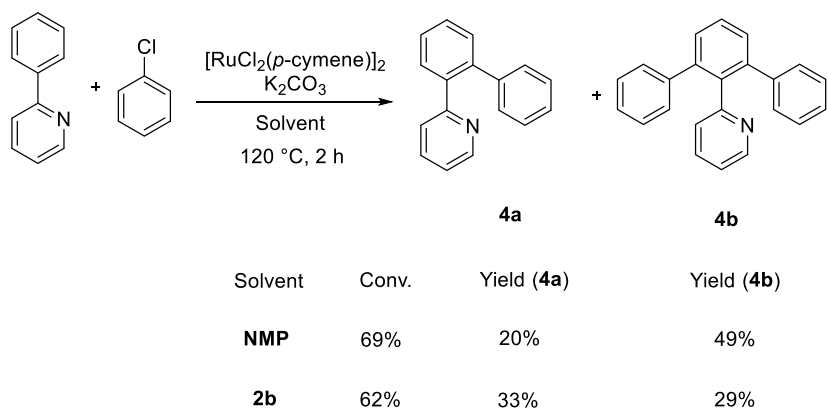

Scheme $\mathbf{5}$. Use of $\mathbf{2 b}$ as an alternative solvent to NMP

In summary, we have developed selective and efficient catalytic system for the reductive amination of LA and primary 
amines to $N$-substituted-5-methyl-2-pyrrolidones. This catalytic system operates at low catalyst loading and hydrogen pressure under neat conditions. This catalyst efficiently transforms a variety of amines including very bulky and functional ones. The catalytic system is also applicable to synthesis $N$ arylisoindolinone derivatives. This mild and green catalytic system provides a general protocol for converting biomassbased chemicals into value added products.

\section{Experimental Section}

Levulinic acid (98\%), amines and 2-formylbenzoic acid were purchased from Sigma-Aldrich and used as received. Solvents (methanol, diethyl ether, water) were HPLC grade and used as received. Ir1 was synthesized according to a reported procedure.[20] NMR spectra were recorded on Bruker Avance ( $300 \mathrm{MHz}$ or $400 \mathrm{MHz}$ ) instruments.

General procedure for the reductive amination of LA: Amine (2 mmol), Ir1 $(0.05-0.1 \mathrm{~mol} \%)$, levulinic acid $(2 \mathrm{mmol})$ were placed in a $20 \mathrm{ml}$ autoclave. The reactor was flushed with $\mathrm{H}_{2}$ and then pressurized with 5 bar of $\mathrm{H}_{2}$ under stirring. Once the required pressure was reached, the reactor was maintained connected for an additional 2 minutes before closing. The mixture was stirred at the appropriate temperature for the desired time. The reactor was cooled down and carefully depressurized. The reaction mixture was analyzed by ${ }^{1} \mathrm{HNMR}$ and directly purified by flash column chromatography using petroleum ether and ethyl acetate with 1 vol\% triethylamine as eluent.

General procedure for the sequential dehydration/reductive amination from glucose: $(0.45 \mathrm{~g}, 2.5 \mathrm{mmol})$ was loaded into a $20 \mathrm{~mL}$ autoclave, and $\mathrm{H}_{2} \mathrm{SO}_{4}(2.5 \mathrm{~mL}, 0.5 \mathrm{~mol} / \mathrm{L})$ was added. The autoclave was quickly heated to $170{ }^{\circ} \mathrm{C}$, and vigorously stirred for $2 \mathrm{~h}$ at the same temperature. The reaction mixture was allowed to cool to room temperature before addition of a $1 \mathrm{M}$ sodium bicarbonate solution until $\mathrm{pH} 7$. Insoluble solid byproducts were removed by filtration. The hydrolysis filtrate was transferred to a $20 \mathrm{~mL}$ autoclave containing the desired amount of catalyst Ir $1(0.05 \mathrm{~mol} \%)$ and aniline (1 equiv.). The reactor was heated in an oil bath at $110{ }^{\circ} \mathrm{C}$ with 20 bar $\mathrm{H}_{2}$ for $16 \mathrm{~h}$. The reactor was allowed to cool down to room temperature and carefully depressurized. The reaction mixture was extracted with dichloromethane $(3 \times 5 \mathrm{~mL})$. The combined organic phases were evaporated to dryness and the crude product was purified by column chromatography on silica gel using petroleum ether / ethyl acetate $(3 / 1 ; \mathrm{v} / \mathrm{v})$ as eluent.

General procedure for the reductive amination of 2-formylbenzoic acid: Amine (2 mmol), Ir1 (0.05 mol\%) and 2-formylbenzoic acid (2 mmol) were placed in a $20 \mathrm{ml}$ autoclave. The reactor was flushed with $\mathrm{H}_{2}$ and then pressurized with 5 bar of $\mathrm{H}_{2}$ under stirring. Once the required pressure was reached, the reactor was maintained connected for an additional 2 minutes before closing. The mixture was stirred at the appropriate temperature for the desired time. The reactor was cooled down and carefully depressurized. The product was directly purified by flash column chromatography using petroleum ether and ethyl acetate with 1 vol\% triethylamine as eluent.

General procedure for the $\mathrm{C}-\mathrm{H}$ arylation: 2-phenylprydine $(0.078 \mathrm{~g}, 0.5$ $\mathrm{mmol})$, chlorobenzene $(0.14 \mathrm{~g}, 1.25 \mathrm{mmol}),\left[\mathrm{RuCl}_{2}(p \text {-cymene })\right]_{2}(0.0077 \mathrm{~g}$, $0.0125 \mathrm{mmol}), \mathrm{K}_{2} \mathrm{CO}_{3}(0.207 \mathrm{~g}, 1.5 \mathrm{mmol})$ and NMP or $\mathbf{2 b}(1.5 \mathrm{~mL})$ were added to a Schlenk tube under an argon atmosphere. The resulting mixture was stirred at $120^{\circ} \mathrm{C}$ for $2 \mathrm{~h}$. The reaction media was cooled down and filtrated over Celite. The crude mixture was analyzed by ${ }^{1} \mathrm{H}$ NMR.

\section{Acknowledgements}

The authors acknowledge the China Scholarship Council for a grant to SW.

\author{
Keywords: biomass• levulinic acid• pyrrolidones• reductive \\ amination• iridium
}

[1] a) J. R. Rostrup-Nielsen, Science 2005, 308, 1421-1422; b) G. W. Huber, S. Iborra, A. Corma, Chem. Rev. 2006, 106, 4044-4098; c) A Corma, S. Iborra, A. Velty, Chem. Rev. 2007, 107, 2411-2502; d) P. Gallezot, Catal. Today 2007, 121, 76-91; e) L. D. Schmidt, P. J. Dauenhauer, Nature, 2007, 447, 914-915; f) G. Yong, Y. Zhang, J. Y. Ying, Angew. Chem. Int. Ed. 2008, 47, 9345-9348; g) J. J. Bozell, G. R. Petersen, Green Chem. 2010, 12, 539-554; h) J. C. Serrano-Ruiz, J. A. Dumesic, Energy Environ. Sci. 2011, 4, 83-99; i) P. Gallezot, Chem. Soc. Rev. 2012, 41, 1538-1558.

[2] a) B. Kamm, Angew. Chem. Int. Ed. 2007, 46, 5056-5058; b) D. M. Alonso,S. G. Wettsteina, J. A. Dumesic, Chem. Soc. Rev. 2012, 41 8075-8098; c) R.-J. van Putten, J. C. van der Waal, Ed de Jong, C. B Rasrendra, H. J. Heeres, J. G. de Vries, Chem. Rev. 2013, 113, 14991597; d) A.Farrán, C. Cai, M. Sandoval, Y. Xu, J. Liu, M. J. Hernáiz, R. J. Linhardt, Chem. Rev. 2015, 115, 6811-6853; e) C. Li, X. Zhao, A. Wang, G. W. Huber, T. Zhan, Chem. Rev. 2015, 115, 11559-11624; f) T. Werpy, G. R. Petersen, Top Value Added Chemicals from Biomass. Volume I - Results of Screening for Potential Candidates from Sugars and Synthesis Gas, U. S. D. o. Energy, 2004. g) J. J. Bozell, G. R. Petersen, Green Chem. 2010, 12, 539-554.

[3] a) Y. Isoda; M. Azuma, Japanese Patent 08053390, 1994; b) L. E. Manzer, U.S. Patent 6743819 B1, 2004; c) L. E. Manzer, U.S. Patent 2006/247443A1, 2006

[4] X.-Y. Liu, C.-H. Li, C.-M. Che, Org. Lett. 2006, 8, 2707-2710

[5] J. Davies, T. D. Svejstrup, D. Reina, N.S. Sheikh, D. Leonori, J. Am Chem. Soc. 2016, 138, 8092- 8095.

[6] M.-C. Fu, R. Shang, W.-M. Cheng, Y. Fu, Angew. Chem. Int. Ed. 2015 54, 9042-9046.

[7] R. L. Frank, W. R. Schmitz, B. Zeidman, Org. Synth. 1947, 27, 28.

[8] a) L. E. Manzer, F. E. Herkes, US Patent 2004192933, 2003; b) L. E. Manzer, WO Pat, 2004084633, 2004

[9] X. L. Du, L. He, S. Zhao, Y. M. Liu, Y. Cao, H. Y. Heand, K. N. Fan Angew. Chem. Int. Ed. 2011, 50, 7815-7819.

[10] J. Zhang, B. Xie, L. Wang, X. Yi, C. Wang, G. Wang, Z. Dai, A. Zheng, F.-S. Xiao, ChemCatChem DOI: 10.1002/cctc.201600739.

[11] A. S. Touchy, S. M. A. H. Siddiki, K. Kon, K.-i. Shimizu, ACS Catal. 2014, 4, 3045-3050

[12] a) G. Chieffi, M. Braun, D. Esposito, ChemSusChem, 2015, 8, 3590 3594; b) C. Ortiz-Cervantes, M. Flores-Alamo, J. J. García Tetrahedron Lett. 2016, 57, 766-771; c) J. D. Vidal, M. J. Climent, A Corma, D. P. Concepcion, S. Iborra, ChemSusChem 2017, 10, 119-128 d) Z. Sun, J. Chen, T. Tu, Green Chem. 2017, 19, 789-794; e) T. Zhang Y. Ge, X. Wang, J. Chen, X. Huang, Y. Liao, ACS Omega 2017, 2, 3228-3240; f) G. Gao, P. Sun, Y. Li, F. Wang, Z. Zhao, Y. Qin, F. Li, ACS Catal. 2017, 7, 4927-4935.

[13] Y. B. Huang, J. J. Dai, X. J. Deng, Y. C. Qu, Q. X. Guo, Y. Fu, ChemSusChem, 2011, 4, 1578-1581.

[14] Y. Wei, C. Wang, X. Jiang, D. Xue, J. Li, J. Xiao, Chem. Commun 2013,49, 5408-5410;

[15] Z. Xu, P. Yan, H. Jiang, K. Liu, Z. C. Zhang, Chin. J. Chem. 2017, 35, 581-585

[16] a) Y. Ogiwara, T. Uchiyama, N. Sakai, Angew. Chem. Int. Ed. 2016, 55, 1864-1867; b) C. Wu, X. Luo, H. Zhang, X. Liu, G. Ji, Z. Liu, Z. Liu, Green Chem. 2017, DOI: 10.1039/C7GC00999B;

[17] A. Ledoux, L. S. Kuigwa, E. Framery, B. Andrioletti, Green Chem. 2015, $17,3251-3254$ 
[18] Y. Wei, C. Wang, X. Jiang, D. Xue, Z.-T. Liu, J. Xiao, Green Chem. 2014, 16, 1093-1096

[19] J. D. Vidal, M. J. Climent, D. P. Concepcion, A. Corma, S. Iborra, M. J. Sabater, ACS Catal. 2015, 5, 5812-5821.

[20] S. Wang, H. Huang, V. Dorcet, T. Roisnel, C. Bruneau, C. Fischmeister, Organometallics, 10.1021/acs.organomet.7b00503

[21] a) J. T. Link, S. Raghavan, S. J. Danishefsky, J. Am. Chem. Soc. 1995 117, 552-553; b) M. H. Norman, D. J. Minick, G. C.Rigdon, J. Med Chem. 1996, 39, 149-157; c) F. A. Luzzio, A. V. Mayorov, S. S. W. Ng E. A. Kruger, W. D. Figg, J. Med. Chem. 2003, 46, 3793-3799;d) D. L. Comins, S. Schilling, Y. Zhang, Org. Lett. 2005, 7,95-98; e) C Riedinger, J. A. Endicott, S. J. Kemp, L. A. Smyth, A. Watson, E. Valeur B. T. Golding, R. J. Griffin, I. R. Hardcastle, M. E. Noble, J. M.
McDonnell, J. Am. Chem. Soc. 2008, 130, 16038-16044; f) A. Verma, S. Patel, M. A. Meenakshi, A. Kumar, A. Yadav, S. Kumar, S. Jana, S.S harma, C. D. Prasad, S. Kumar, Chem. Commun. 2015, 51, 1371-1374 [22] D. Prat, J. Hayler, A. Wells, Green Chem. 2014, 16, 4546-4551.

[23] W. Li, P. Arockiam, C. Fischmeister, C. Bruneau, P. Dixneuf, Green Chem. 2011, 13, 2315-2319.

[24] Lower boiling point ethylamine and methylamine were not considered in this study but it can be anticipated that they would lead to $\mathrm{N}$-alkyl-5methyl-pyrrolidone derivatives with boiling points below $248^{\circ} \mathrm{C}$. 